\title{
PERANAN BAGIAN OPERASIONAL DALAM MENANGANI KEDATANGAN DAN KEBERANGKATAN KAPAL ASING PADA PT. ALTA MARITIM INDONESIA CABANG MEDAN BELAWAN
}

\author{
${ }^{1}$ Dirhamsyah,SE.,M.Si, ${ }^{2}$ Dina Rispianti, SE., M.Si, ${ }^{3}$ Ayu Damaianti Situmeang \\ ${ }^{1,2,3}$ KPNK, Politeknik Adiguna Maritim Medan \\ email: dirhamsyahami@gmail.com
}

\begin{abstract}
Abstrak. Pada dasarnya peranan bagian operasional dalam menangani kedatangan dan keberangkatan kapal asing tidak terlepas dari batasbatas dan tanggung jawab dari perusahaan pelayaran karena pentingnya peranan operasioanl pada perusahaan pelayaran PT. Alta Maritim Indoneia Medan menerapkan fungsi dan proses manajemen dalam kegiatan sehari-hari. Dimana penerapan fungsi manajemen tersebut berasal dari perencanaan perusahaan mempunyai tujuan tertentu, dimana tujuan merupakan suatu tantangan dalam mencapai tujuan, dalam mencapai tersebut adalah perencaan manajer dapat menangani masalah atau kegiatan yang telah digariskan dalam perencanaan PT. Alta Maritim Indoneia Medan. Dalam melaksanakan clearance yang perlu agar dapat dimengerti dan diikuti dengan baik, maka yang perlu diamati misalnya proses pengurusan clearance dilaksanakan oleh agen dengan instansi - instansi yang berwenang, seperti kantor Otoritas Pelabuhan, Bea dan Cukai, Imigrasi, Karantina lancarnya proses penanganan clearance berarti lancarnya masuk dan keluarnya kapal dari pelabuhan sesuai dengan rencana pelayaran. Sebaliknya terjadinya hambatan karena terkendalanya pengurus dokumen muatan, habisnya masa berlaku dokumen atau kurang harmonisnya komunikasi pendekatan antara agen dengan salah satu atau beberapa instansi yang berwewenang.Tidak lancarnya efisien proses pengurusan clearanceakan menimbulkan resiko antara lain meningkatnya biaya operasi kapal yang dipelabuhan dengan hilang nya hari layar kapal yang telah direncanakan dalam commintion days kapal.
\end{abstract}

Kata Kunci: Crew Asing, Imigrasi, dan PT.Eka Nusantara Cabang Belawan.

\begin{abstract}
Basically the role of the operational department in handling the arrival and departure of foreign ships cannot be separated from the boundaries and responsibilities of the shipping company because of the important operational role of the shipping company PT. Alta Maritim Indonesia Medan implements management functions and processes in daily activities. Where the implementation of the management function comes from the company's planning has a specific goal, where the goal is a challenge in achieving the goal, in achieving this is planning managers can handle problems or activities that have been outlined in the planning of PT. Alta Maritim Indonesia Medan. In carrying out the necessary clearances so that they can be understood and followed properly, it is necessary to observe for example the clearance process is carried out by agents with authorized agencies, such as the Port Authority, Customs and Excise offices, Immigration, Quarantine, the smooth handling of the clearance process means smooth entry. and the discharge of the ship from the port in accordance with the shipping plan. On the other hand, obstacles occur due to problems with cargo document management, expiration of document validity periods or lack of harmonious approach communication between agents and one or
\end{abstract}


more authorized agencies. The non-efficient process of managing clearance will cause risks, among others, increasing operating costs of ships in port with the loss of sailing days. ships that have been planned in the ship's commission days.

Keywords: Crew Foreign, Imigrasi, PT.Eka Nusantara Cabang Belawan

\section{PENDAHULUAN}

Perusahaan pelayaran adalah suatu komponen yang mempunyai handling yang besar di dunia pelayaran untuk pengelolaan terhadap pelayanan kapal dan barang. Peranan dan fungsi bagian operasional perusahaan pelayaran haruslah menguntungkan, kualitas profesionalisme yang tinggi. Sebab kwalitas dalam melayani kapal dan membawa dampak terhadap perushaan pelayaran itu sendiri maupun pelabuhan tempatnya melakukan kegiatan.

Salah satu dampaknya terhadap perusahaan pelayaran PT. Alta Maritim Indonesia Cabang Medan Belawan bila pelayanan yang diberikan sebaik mungkin akan menjamin mereka untuk tetap mempercayai perusahaan yang ditunjuk oleh ship owner untuk menangani kapal dan muatannya. Akan tetapi jika pelayanan kapal dan peranan fungsi operasional perusahaan pelayaran tidak sesuai yang di harapkan oleh ship owner maka mereka tidak akan memakai jasa perusahaan tersebut dan akan mencari lagi perusahaan pelayaran yang lain untuk menangani kapal mereka.

Berdasarkan kenyataan di atas bahwa baik buruknya pelayanan yang diberikan perusahaan terhadap kapal tergantung dari pengelolaan perusahaan secara operasional. Melihat tata kerja atau peranan dan fungsi bagian operasional merupakan suatu dari perusahaaan yang memegang peranan penting dalam perusahaan pelayaran. Penulis merasa tertarik mencoba mendalami serta mempelajari sejauh mana nama peranan dan fungsi bagian operasional pada PT. Alta Maritim Indonesia Cabang Medan Belawan.

Dalam melaksanakan clearance yang perlu agar dapat dimengerti dan diikuti dengan baik, maka yang perlu diamati misalnya proses pengurusan clearance dilaksanakan oleh agen dengan instansi instansi yang berwenang, seperti kantor Otoritas Pelabuhan, Bea dan Cukai, Imigrasi, Karantina lancarnya proses penanganan clearance berarti lancarnya masuk dan keluarnya kapal dari pelabuhan sesuai dengan rencana pelayaran. Sebaliknya terjadinya hambatan karena terkendalanya pengurus dokumen muatan, habisnya masa berlaku dokumen atau kurang harmonisnya komunikasi pendekatan antara agen dengan salah satu atau beberapa instansi yang berwewenang.

\section{METODE PENELITIAN}

Dalam menyusun makalah tentunya membutuhkan bahan - bahan dan fakta yang dapat mendukung penulisan sehingga dimengerti dan dipahami oleh pembaca. Dalam hal ini dibutuhkan beberapa kumpulan baik yang di ambil dari buku buku maupun hasil pengamatan yang dilakukan ada beberapa metode yang dipergunakan dalam penyusunan sebuah makalah atau tulisan ilmiah antara lain:

1).Metode Penelitan Lapangan (Field Research)

Dalam metode ini penulis mengamati langsung bagaimana cara kerja perusahaan dalam melayani kedatangan kapal dan kerberangkatan kapal serta mengamati langsung bagaimana aktifitas kegiatan dipelabuhan baik pada saat kapal berada di labuh maupun pada saat kapal sandar dipelabuhan.

2). Metode Penelitian Kepustakaan ( Library Research )

Dalam metode ini penulis memperoleh data dari buku - buku dan majalah tentang kepelabuhan serta dokumen yang telah dipelajari yang menjadi pedoman bagi penulis dalam menyusun makalah ini.

\section{HASIL DAN PEMBAHASAN}

\section{A.Sejarah Singkat Perusahaan}

PT. Alta Maritim Indonesia Medan adalah perusahaan pelayaran yang berdiri sejak 03 Desember 1999 di Medan Belawan. PT. Alta Maritim Indonesia beralamat di JL.Raya Pelabuhan Gabion no 1C. PT. Alta Maritim Indonesia melayani jasa seperti: trip charter, time charter. PT. Alta Maritim Indonesia mendukung kapal dengan muatan container, Tug \& Barge, LCT dan kapal Tanker. 
Dengan konsentrasi usaha dibidang jasa keagenan angkutan pelayaran, pengurusan Crew dan kelengkapan dokumen kapal.pengurusan dan hubungan relasi angkutan kapal serta kemampuan yang handal dalam pelayanan serta kesigapan dalam penyediaan dalam segala hal yang berkaitan dengan hubungan pelayaran modal perusahaan dalam melayani kebutuhan pengguna jasa.

\section{B.Peranan Bagian Operasional Dalam Menangani Kedatangan dan Keberangkatan Kapal Asing.}

Pada dasarnya peranan bagian operasional dalam menangani kedatangan dan keberangkatan kapal asing tidak terlepas dari batas-batas dan tanggung jawab dari perusahaan pelayaran karena pentingnya peranan operasioanl pada perusahaan pelayaran PT. Alta Maritim Indoneia Medan menerapkan fungsi dan proses manajemen dalam kegiatan sehari-hari. Dimana penerapan fungsi manajemen tersebut berasal dari perencanaan perusahaan mempunyai tujuan tertentu, dimana tujuan merupakan suatu tantangan dalam mencapai tujuan, dalam mencapai tersebut adalah perencaan manajer dapat menangani masalah atau kegiatan yang telah digariskan dalam perencanaan PT. Alta Maritim Indoneia Medan.

Perencanaan sumber daya manusia merupakan salah satu fungsi dari manajemen sumber daya manusia yang mengorientasikan bagaimana menyusun langkah-langkah strategi dan menyiapkan sumber daya manusia atau karyawan dalam proses seleksi terdapat penyemputan bidang calon pekerja yang dibutuhkan dan akhirnya mengarah kepada penawaran pekerjaan satu orang atau sekelompok calon pekerja.

Pada hakikatnya perencanaan mengandung perbuatan melihat ke depan, memikirkan jauh sebelumnya dan menggambarkan lebih dahulu sebagai dasar untuk proses penyelenggaraan mencapai tujuan karena perencanaan adalah penentuan serangkaian kegiatan tindakan untuk mencapai suatu hasil yang diinginkan .

\section{C.Jenis Dokumen dan Sertikat Yang Terkait Pada Pelayanan Kapal}

Dalam pengurus dokumen yang ditangani oleh PT. Alta Maritim Indoneia Medan untuk prosedur pelayanan dokumen kapal adalah:

1).Sertifikat Kapal

Sertifikat kapal adalah syarat atau sistem managemen keselamatan yang bertujuan untuk menjamin kelayakan operasional dengan aman serta legalitas yang akan berlayar dan mengerjakan sebuah proyek. Sertifikat kapal tersebut adalah salah satu persyaratan untuk pengurusan dokumen clearance, adapun jenis sertifikat untuk kapal local adalah:

a).Certificate Nationality/Surat Laut

b).Internatuonal Tonnage Certificate/Surat Ukur internasional

c).Minimum Safe Manning Document/Dokumen keselamatan pengawakan minimum.

d).Cargo Ship Safety Contruction Certificate/sertifikat keselamatan konstruksi kapal barang

e).Cargo ship safety Contrukstion Equitment Certificate/sertifikat keselamatan perlengkapan kapal barang.

f).Cargo Ship Safety Radio Certificate/Sertifikat keselamatan radio kapal

g).Safety Management Certificate/Sertifikat management keselamatan

h).Internal oil Population Certificate/sertifikat nasional pencegahan pencemaran oleh minyak

i).Document of complicate/dokumen penyesuaian manajemen

j).Safety management certificate/sertifikat manjemen keselamatan

k)Document of classification for manchinery/sertifkat kalsifikasi mesin.

2).Certificate of classification for hull/sertifikat klasifikasi lambung

m).International load line certificate/sertifikat garis muat internasioanal

n)..Life raft/alat keselamatan

o). $\mathrm{CO} 2$ Certificate/Sertifikat $\mathrm{CO} 2$

p).Indonesian healt Book/ Buku Kesehatan Indonesia
3).Dokumen Crew
a).Ijazah Pelaut
b).Endorsment, Sertifikat Tanda Pengukuhan
c).Sertifikat Keahlian Pelaut
d).Buku Pelaut
e).Pasport

3).Dokumen Pendukung

a).Penunjukan keagenan

Dokumen ini dikeluarkan oleh principal yang akan di serahkan kepada perusahan pelayaran yang akan menangani semua kebutuhan kapal selama berada di pelabuhan yang di singgahinya.

b).Persetujuan Keagenan Kapal Asing (PKKA)

Surat persetujuan bagi perusahaan angkutan laut nasional/penyelenggaraan kegiatan angkutan laut khusus untuk mengageni kapal-kapal asing yang 
menyinggahi pelabuhan-pelabuhan yang terbuka untuk perdagangan luar negeri.

\section{4).Dokumen Barang}

\section{a).Manifest}

Manifest dikeluarkan oleh perusahaan pelayaran yang berisikan keterangan barang yang dimuat di kapal yang terperici mengenai:

1).Jenis barang

2).Jumlah barang

3).Nama pengirim

5).Nama penerima.

b).Bill Of Lading

Bill Of Lading dikeluarkan oleh perusahaan pelayaran dan mempunyai fungsi sebagai berikut:

1).Bukti bahwa barang telah di muat di kapal

2).Dokumen hak milik dari pemilik barang

3).Dokumen jual/beli

\section{D.Peranan Pelayanan Dokumen Kapal}

1).Sebelum Kapal Tiba.

Sebelum kapal tiba, Prinsipal (pemilik kapal) mengadakan kontak atau komunikasi dengan pihak perusahaan atau agen yang di tunjuk, untuk pemberitahuan ini dilaksanakan 1-2 hari sebelum kapal tiba agar pihak perusahaan pelayaran dapat mempersiapkan segala sesuau yang di butuhkan. Prinsipal sebelum membuat Letter of Appoitment (surat persetujuan) yang di tunjuk kepada perusahaan pelayaran. Surat ini dibuat dengan maksud apabila kapal membutuhkan sesuatu maka kapal dapat meminta pada agen yang ditunjuk oleh prinsipal.

Ketika sudah terjadi persetujuan antara agen dan pihak owner maka agen akan meminta sebagian dokumen kapal diantaranya:

a.Surat Laut

b.Surat Ukur

c.Penjukan Keagenan

d.Ship Particular

e.Rencana Pola Trayek (RPT)

f. B/L atau Manifest

Dokumen diatas dapat di e-mailkan dengan tujuan untuk membuat Pemberitahuan Kedatangan Kapal (PKK) yang akan diurus di Kantor Syahbandaran dan Otoritas Pelabuhan (KSOP).

Setelah mengetahui kapal yang akan datang maka perusahaan pelayaran membuat rencana operasi kedatangan kapal yang diajukan pada Instansi-intansi yang terkait didalam lingkungan kerja Pelabuhan, antara lain:

1).Kantor Syahbandaran dan Otoritas Pelabuhan (KSOP).
2).Vessel Trafic Services (VTS)

3).Karantina Kesehatan.

Pengurusan dokumen yang pertama dikalukan oleh pihak agen adalah pihak agen akan mengajukan Permohonan Pemberitahuan Kedatangan Kapal (PKK) yang akan diserahkan kepada Kantor Syabandar dan Otoritas Pelabuhan (KSOP) panjang sebagai pemberitahuan atas kapal yang akan tiba.

Persyaratan Permohonan Kedatangan Kapal (PKK) yaitu:
a).Formulir checklist persyaratan PKK
b).Permohonan PKK
c).Bill Of Lading (B/L)
d).Penunjukan Keagenan
e).Ship Particular
f).Rencana Pola Trayek (RPT)
g).Surat Ukur

\section{2).Setelah Kapal Tiba}

Setelah kapal tiba di wilayah pelabuhan yang di singgahi, maka kapal akan melakukan penurunan jangkat di wilayah Anchorage Area yang sudah ditentukan oleh agen. Sebelum agen memastikan dimana tempat dermaga yang akan digunakan, kapal akan tetap berada di Anchorage Area. Saat kapal masih berada di wilayah area labuh, agen akan pergi ke kapal menggunakan boat service guna mengambil dokumen kapal. Dan pada saat agen sudah berada di atas kapal, agen akan memimta ijin kepada kapten kapal untuk mengecek dan membawa dokumen kapal tersebut yang meliputi:

Selain mengambil dokumen kapal, agen juga mengambil dokumen Crew kapal (anak buah kapal) yaitu:

\section{a.Sertifikat kapal \\ b.Buku kesehatan kapal \\ c.Ijazah crew \\ d.Buku pelaut}

Setelah dokumen tersebut sudah dibawa oleh agen, maka dokumen tersebut akan serahkan ke kantor syahbandar dan otoritas pelabuhan untuk di memorandum. Apabila ada sertifikat yang sudah habis masa berlakunya maka agen segera akan melaporkan ke owner untuk memberi tahukan bahwa sertifikat tersebut harus diperpanjang.

\section{3).Pengurusan Clearence In}

Saat proses clearence in agen akan mengurus berkas di Kantor Syahbandar dan Otoritas Pelabuhan (KSOP) diantaranya:

a).Laporan Kedatangan dan Keberangkatan Kapal (LK3)

Laporan yang disampaikan oleh perusahan pelayaran kepada Kantor Syahbandar dan Otoritas 
Pelabuhan tentang realisasi kegiatan kapal yang berisikan tanggal kapal tiba dan kapal berangkat, pelabuhan asal dan pelabuhan tujuan, serta data muatan kapal (bongkar/muat).

Persyaratan permohonan LK3 Yaitu:

1).Formulir chacklist Laporan Kedatangan dan Keberangkatan Kapal (LK3)

2).Permohonan Laporan Kedatangan dan

Keberangkatan Kapal (LK3)

3).Penunjukan Keagenan

4).Rencana Pola Trayek (RPT)

b).Memorandum dokumen kapal pengecekan dokumen kapal oleh petugas Kantor Syabandar dan Otoritas Pelabuhan (KSOP). Dimana di dalam memorandum tersebut disertakan:

1).Klasifikasi dokumen kapal tersebut

2).Jenis dokumen kapal tersebut

3).Tempat dimana diterbitkan dokumen tersebut, lengkap dengan masa diterbitkan dan masala berkakunya

4).Identitas kapal dan nama nahkoda serta perusahan agen yang mengageni.

5).Warta kapal.

6).Tanggal kapal tiba dan tanggal kapal berangkat

7).Nama pelabuhan asal dan pelabuhan berikutnya

c).Permohonan barang berbahaya berisikan izin memuat muatan barang berbahaya yang disetujui oleh Kantor Syahbandar dan Otoritas Pelabuhan (KSOP) Persyratan permohonan barang berbahaya untuk batubara:

1).Formulir chacklist persyaratan ijin barang berbahaya

2).Permhonan ijin barang berbahaya

3).Bil Of Lading (B/L)

4). Pemberitahuan Kedatangan Kapal (PKK) yang sudah ditandatangani oleh petugas Kantor Syahbandar dan Otoritas Pelabuhan (KSOP).

d).Permohonan Olah Gerak , surat yang berisikan tenteng izin gerak kapal yang di setujui oleh Kantor Syahbandar dan Otoritas Pelabuhan (KSOP).

Persyaratan permohonan olah gerak yaitu:

1).Formulir Chacklist persyaratan penerbitan surat persetujuan olah gerak kapal

2).Permohonan persetujuan kegiatan olah gerak

3).Polis asuransi

4).Rencana Pola Trayek (RPT)

5).Surat Penunjukan keagenan

6).Surat Persetujuan Kegiatan Bongkar Muat (SPKBM).
Setelah mengajukan permohonan tersebut yang sudah ditandatangan dan disetujui oleh pihak Kantor Syahbandar dan Otoritas Pelabuhan, agen akan mengirimkan surat ijin gerak kapal, surat ijin barang berbahaya ke pada pihak PT. Alta Maritim Indonesia sebagai bukti jika kita sudah melaksanakan kegiatan persyaratan untuk kapal sandar.

Adapun dokumen yang akan dikirimkan oleh agen adalah:

a).Pemperitahuan Kedatangan Kapal (PKK)

b).Surat Laut

c).Surat Ukur

d).Ijin gerak kapal

Setelah sudah disetujui, oleh pihak PT. Alta Maritim Indonesia akan menerbitkan Uang Perkapalan (UPER) untuk pandu tunda yang akan digunakan di area pelabuhan PT. Alta Maritim Indonesia, biaya UPER tersebut biasanya ada perhitungan tersendiri antara pengelola pandu dan pihak agen kapal, setelah biaya tersebut sudah disepakatidan sudah melakukan pembayaran Uang Perkapalan (UPER) tersebut kapal pandu tunda siap untuk digerakkan.

e).Pembayaran labuh, rambu Vessel Trafic Services (VTS), Penerimaan Uang Perkapalan (PUP) barang berbahaya saat pengurusan surat seperti Pemberitahuan Kedatangan Kapal (PKK), Permohonan Barang berbahaya agen akan sekaligus meminta nota untuk pembayaran Penerimaan Negara Bukan Pajak (PNBP) dari Kantor Syabandar dan Otoritas Pelabuhan (KSOP) dan Kantor Vessel Trafic Services (VTS).

1).Labuh dikenakan saat kapal melakukan penurunan jangkar di wilayah labuh perhitungan biaya yaitu jumlah GT dikalikan dengan 87 Rupiah (Lazimnya kapal dalam Negeri)

2).Rambu dikenakan saat kapal menggunakan peralatan atau sistem yang berada di luar kapal yang didesain dan dioperasikan untuk meningkatkan keselamatan dan efesieni bernavigasi kapal dan/atau lintas kapal perhitungannya yaitu jumlah GT dikalikan dengan 250 Rupiah (Lazimnya kapal dalam negeri)

3).Vessel Trafic Services (VTS) biaya telekomunikasi khusus untuk kepentingan diatas pelayaran yang merupakan setiap pemancar, mengirimkan dan penerimaan setiap jenis tanda, gambar, suara dan informasi dalam bentuk apapun melalui sistem kawat optik, radio atau sistem elektromagnetik lainnya dalam pelayaran. Biaya yang dikenakan digunakan di Vessel Trafic Services (VTS) yang mana untuk GT 1.000 sampai GT 3.000 
biaya yang harus dibayar sebesar Rp. 125.000 (untuk kapal lokal)

4).Penerimaan Uang Perkapalan (PUP) Barang berbahaya biaya khusus untuk muatan barang berbahaya, contohnya: batubara. Perhitungan biayanya untuk batubara yaitu dikalikan 25 Rupiah (untuk muatan curah padat) dari volume atau muatan kapal tersebut, contoh: (Rp.25 x 10.000 M/T= Rp.250.000,00).

Setelah mendapatkan semua nota tersebut agen akan melakukan pembayaran semua nota tagihan Penerimaan Negara Bukan Pajak (PNBP) melalui SIMPONI (Sistem Informasi PNBP Online) kemudian billing beserta bukti pembayaran jasa labuh, jasa Vessel Trafic Services (VTS), jasa rambu, dan jasa PUP barang berbahaya dari bank dan doserahkan kepada bendahara kantor Kesyabandaran Dan Otoritas Pelabuhan (KSOP) untuk menerbitkan kwitansi lunas.

\section{4).Pengurusan Clearence Out}

Semua kapal yang melaksanakan bongkar atau muat pihak dari PT. Alta Maritim Indonesia sebagai agen akan memonitoring kegiatan tersebut, agar dapat mengetahui waktu selesainya bongkar atau muat.

Berdasarkan pantauan dilapangan maka PT. Alta Maritim Indonesia akan melaksanakan proses keberangkatan kapal yaitu dengan mengajukan kepada:

\section{a).Karantina Kesehatan}

Pertama agen akan melakukan pengajuan permohonan surat persetujuan berlayar ke kantor kesehatan pelabuhan melalui sistem intormasi kesehatan pelabuhan (SIMKESPEL) dengan mengisi data kapal seperti Gross Tonage, pelabuhan sebelum dan pelabuhan selanjutnya, kemudian agen akan membayar jasa pemeriksaan kapal dimana biaya yang dikenakan pada kapal kapal local

Setelah pihak agen melaksanakan pendaftaran dan pembayaran tersebut pihak karantina melakukan pemeriksaan terhadap dokumen-dokumen dan kesehatan kapal yang apabila tidak ada menyimpang kapal akan diijinkan berlayar.

Adapun dokumen kelengkapan yang akan dibawa ke kantor kesehatan pada saat pengambilan surat persetujuan berlayar yang akan di tandatangani oleh petugas tersebut adalah: Laporan kedatangan Keberangkatan, Billing pembayaran yang di lakukan dari Sistem Informasi PNBP online (SIMPONI).

b).Kantor Syahbandar dan Otoritas Pelabuhan (KSOP)
Selanjutnya agen akan mengrus berkas-berkas di syabandar guna melaksanakan proses clearence out. adapun yang diajukan oleh agen yaitu:

1). Permohonan Surat Persetujuan Berlayar

Surat persetujuan berlayar yang akan dikeluarkan oleh Syahbandar adalah surat yang paling penting untuk kapal bias keluar dari daerah pelabuhan dan dan memasuki daerah pelabuhan berikutnya.

Syarat untuk permohonan surat persetujuan berlayar adalah:

a).Formulir Chacklist Penerbitan Surat Persetujuan Berlayar

b).Permohonan Surat Persetujuan Berlayar

c).Bukti data Memorandum Dokumen kapal

d).Last port clearence

e). Crew list

f).Manifest

g).Laporan Kedatangan dan Keberangkatan kalapal (LK3)

h).Bukti foto copy kwitansi lunas (Labuh, Rambu, VTS dan PUP Barang berbahaya)

\section{2).Permohonan crew list}

crew list awak kapal, permohonan crew list buat oleh agen kapal dan diajukan ke kantor syabandar dan otaritas pelabuhan guna untuk meminta persetujuan bahwa data nama-nama yang tertera di crew list tersebut berada di atas kapal.

Syarat-syarat untuk membuat permohonan crewlist adalah:

a)..Formulir chacklist pengesahan crew kapal

b)..Permohonan pengesahan crew kapal

c).Crewlist

Setelah mengajukan permohonan tersebut, agen akan membawa dokumen kapal, lamiran lainnya seperti: Laporan Kedatangan dan Keberangkatan Kapal (LK3), Olah Gerak Kapal, Ijin Barang Berbahaya, kwitansi lunas PNBP serta membawa buku kesehatan kapal yang sudah mendapatkan ijin berlayar oleh kesehatan pelabuhan ke kantor syahbandar di seksi penjagaan dan keselamatan. Setelah semua persyaratan terpenuhi petugas syahbandar akan memprosesnya sesuai antrian oleh agen lain.

Setelah agen selesai melakukan clearance Out kemudian pihak agen pelayaran akan membawa dokumen kapal ke kantor untuk melakukan pemeriksaan, setelah di periksa dan tidak ada kekurangan dan kesalahan dalam mengetikan Surat Persetujuan Berlayar kemudian dokumen tersebut baru ke atas kapal menemui Nahkoda dan menyerahkan dokumen yang di ambil oleh agen dari 
kapal setelah berada di area labuh untuk melakukan clearance in dan clearance Out pada kapal dan biasanya Nahkoda selalu memeriksa kembali dokumen yang telah terima dari agen kapal untuk memastikan tidak ada kehilangan dan kerusakan pada dokumen kapal tersebut.

\section{E.Kendala Yang Dihadapi Pada Saat Penanganan Pelayanan Dokumen Kapal}

Dalam masalah kegiatan Prosedur Pelayanan Dokumen Kapal Oleh PT. Alta Maritim Indonesia masih sering ditemui kendala. Dalam kendala ini yang sering terjadi dalam prosedur penyandaran kapal oleh PT. Alta Maritim Indonesia adalah sebagai berikut:

1).Saat pengurusan dokumen clearance terkadang agen sering memeriksa dokumen kapal ditemukan adanya sertifikat yang habis masa berlakunya. Maka agen harus memperpanjang dokumen tersebut terlebih dahulu. Perpanjangan dokumen tersebut memakan waktu sehingga memperlambat proses pengurusan dokumen kapal.

2).Terlambatnya biaya untuk perpanjangan sertifikatsertifikat kapal dari pemilik kapal sehingga kapal tidak diboleh sandar dan clearance out tidak dapat dilaksanakan karena sertifat yang mati belum di perpanjang masa berlakunya

\section{F.Instansi-Intansi Yang Terkait Dalam Pelayanan Dokumen Kapal}

1).Kantor Syahbandar Dan Otoritas Pelabuhan (KSOP)

Syahbandar adalah instansi yang melaksanakan port clearance, yaitu pemeriksaan surat-surat kapal agar kapal dapat keluar masuk pelabuhan. Syahbandar adalah penegak hukum dalam ketertiban Bandar dan pengawas keselamatan pelayaran kapal- kapal layak laut serta telah memenuhi syarat dan ketentuan keselamatan pelayaran.

2).Kantor Kesehatan Pelabuhan

Kantor kesehatan pelabuhan di bentuk sebagai unit pelaksana teknis departemen kesehatan yang berperan sangat penting dan stategis dalam melakasakan fungsi cegah dan tanggal penyakit karantina dan penyakit menular potensi wadah, meminalisasi resiko yang timbul dengan melaksanakan kegiatan ke karantina, kantor ksehatan pelabuhan adalah bagian dari kantor kesehatan yang bertugas melayani dan bertaggung jawab atas kesehatan kapal dan crew kapal, selain itu juga bertugas memeriksa kesehatan kapal dan crew kapal pada saat tiba dan berangkat ke pelabuhan selanjutnya.

\section{3).Vessel Trafic Services (VTS)}

Sistem monitoring lalu lintas pelayaran yang diterapkan oleh pelabuhan atau suatu menejemen armada perkapalan. Prinsipnya yang digunakan sama seperti sistem yang dipakai oleh Air Trafic Control (ATC) pada dunia penerbangan. Biasanya secara sederhana VTS menggunakan radar, Closed Circuit Television (CCTV), Frekuensi radia VHF, dan automatic Indentification System (AIS) untuk mengetahui cuaca didalam suatu daerah pelayaran tertentu dan terbatas.

\section{e).Bea dan Cukai}

Dalam melakukan pemeriksaan, pihak bea dan cukai harus menerimah laporan dari pihak agen supaya mendapatkan pelayanan seperti : Petugas Bea dan Cukai akan memeriksa dokumen - dokumen yaitu :

1). Crew List

2).Last port (Voyage Memo) pelabuhan yang terakhir disinggahi

3).Ship store (Daftar Perlengkapan Kapal)

4).Bonded Store (Daftar perbekalan kapal)

\section{f.Imigrasi.}

Dalam hal ini pihak Imigrasi juga mendapatkan laporan dari agen bila akan kedatangan kapal seperti.

1).Pemeriksaan Pasport

2).Pemeriksaan crew list, daftar awak kapal

\section{KESIMPULAN}

Peranan bagian operasional dalam menangani kedatangan dan keberangkatan kapal asing PT. Alta Maritim Indonesia Cabang Medan Belawan sudah efektif tetapi kurang efisien.

\section{DAFTAR PUSTAKA}

Bambang Triadmodjo, Jenis Kapal Dan Muatannya, Jakarta : Gramedia Pustaka, 2015.

Edy Hidayat, Manajemen Perusahaan Pelayaran. Jakarta: Rajawali Pers, 2015.

Engkos Kosasih, Keagenan, Jakarta : Gramedia Pustaka, 2015.

Kamus Besar Bahasa Indonesia ( Edisi Lux), Widya Karya, Semarang 
Moenir, Kegiatan Pelayanan, Jakarta : Rajawali Pers, 2015.

Undang-Undang Republik Indonesia No. 17 Tahun 2008 Tentang Pelayaran 